\title{
Strength and Surface Roughness of Cross Linking Acrylic Resin \\ Processed by Different Heat Curing Methods \\ Ali Ehsan Kareem"
}

B.D.S., M.Sc.(prosthodontics), Assist. Lec. College of Dentistry - Al-Mustansirya University

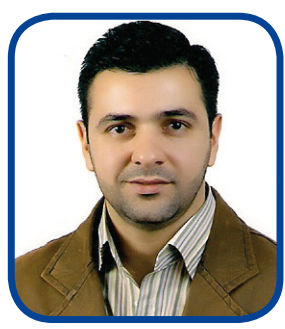

\begin{abstract}
Background: Heat-cured acrylic resin is considered one of the most commonly used denture base material in denture construction, but this material is not ideal in every respect. So many researches have been carried out to find an alternative material like cross linking acrylic resin. Meanwhile, the curing procedures have been modified to improve the physical and mechanical properties of resin materials. The aim of this study was to evaluate the effect of three curing methods:(water bath, autoclave short cycle and autoclave long cycle) on transverse strength, tensile strength and surface roughness of cross linking acrylic denture base materials. Material and method: Cross linking acrylic resin was used in this study and processed in three curing methods (water bath, autoclave short cycle and autoclave long cycle). Ninety specimens were prepared. Each main group was subdivided into three subgroups according to the type of test used (transvers strength test, tensile strength test and surface roughness test). Each group contained 10 specimens for each test.

Result: Three tests were used to analyze the results: analysis of variance (ANOVA), the least significant difference (LSD) and an independent T-test. There were no significant differences between the results of the processing techniques regarding transverse and tensile strength but there was a significant difference between the results of surface roughness tests.

Conclusion: It was concluded that autoclave curing method can be used with different duration whether it is short or long instead of water bath curing method.
\end{abstract}

KEY WORDS

Cross linking acrylic resin, autoclave, water bath, strength, roughness.

CITE THIS ARTCLE:

Kareem A. Strength and surface roughness of cross linking acrylic resin processed by different heat curing methods. Iraqi Dental Journal 2015; 37(1):13-19. http://www.iraqidentaljournal.com

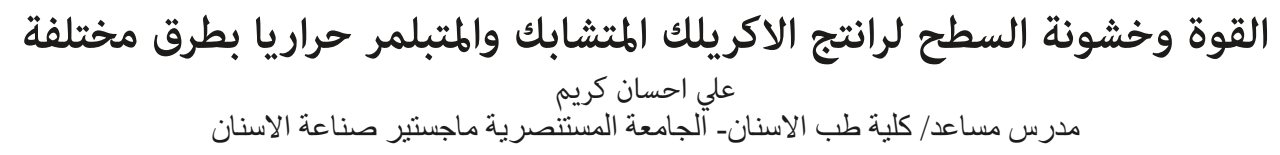

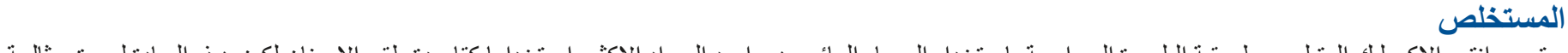

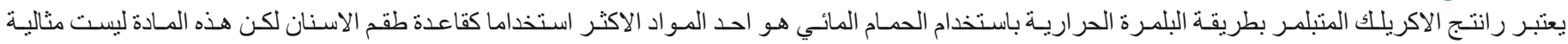

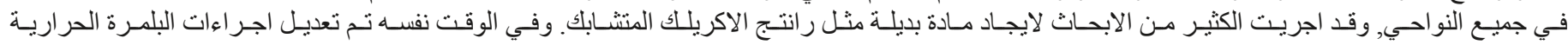

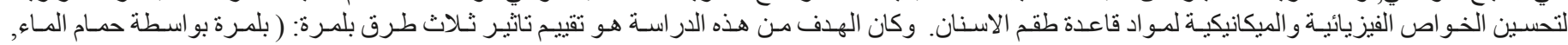

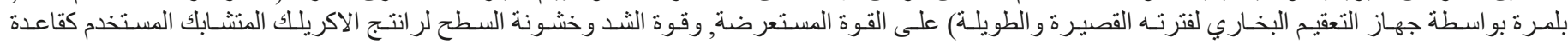
لطقم الاسـنان.

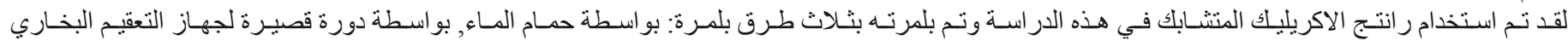

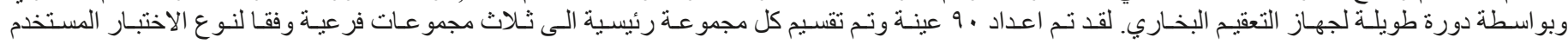

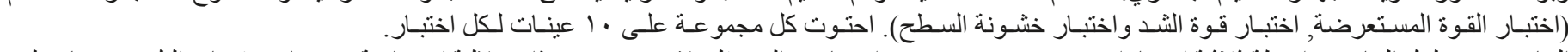

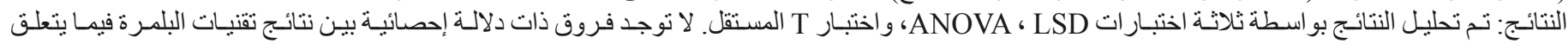

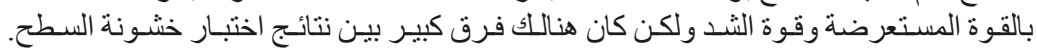

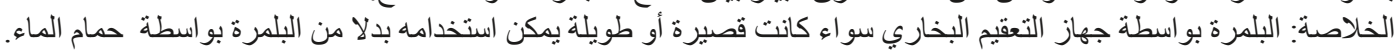

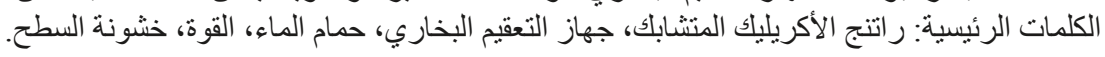

\section{INTRODUCTION}

Poly(methyl methacrylate) (PMMA) is a derivative of acrylic acid, referred to as acrylic resin and it was introduced for use in dentistry in the early 1930s. Since that time it became the most reliable material for denture construction. ${ }^{(1,2)}$ Today the vast majority of dentures made are fabricated from heatcured PMMA and rubber-reinforced PMMA. ${ }^{(3)}$ All denture bases constructed from PMMA polymers or copolymers. ${ }^{(4)}$

This material is not ideal in every respect and it is in combination of various properties rather than one single desirable property that accounts for its popularity and usage. The properties contributed to the success of acrylic resin as a denture base material are excellent appearance, ease in processing, simple processing equipment and ease repair. $(5,6,7)$ In addition, it is characterized by low cost of fabrication, a satisfactory shelf life. ${ }^{(8,9,10)}$ But it does not provide sufficient mechanical requirements of the dental prosthesis. ${ }^{(11)}$ Due to its residual monomer evaporation, this results in polymerization shrinkage, dimensional inaccuracy, rough surface, and porosity. This material has limitation, particularly in term of

\footnotetext{
*: E- mail: ali_ihsan123@yahoo.com
} 
flexural and impact strength. ${ }^{(5,6)}$ Also, Johastone et al. showed that $68 \%$ of acrylic resin dentures break within few years after fabrication ${ }^{(12)}$.

Different trials had been undertaken by many researchers to improve the mechanical properties of PMMA, ${ }^{(6)}$ Such as, reinforcement of different types of fibers ${ }^{(11)}$, metal wires were also used as reinforcement for denture base polymers ${ }^{(13)}$ and the incorporation of fillers, search for an alternative material to PMMA, use of chemical modification, presence of surface treatment or not and using alternative curing method or changing the programed cycle. Strong and more fracture-resistant denture base materials can be obtained by the use of impact modifiers; usually rubber like substances which were added to acrylic resin ${ }^{(14)}$ or by the addition of cross linking agents. ${ }^{(15)}$ Glycol dimethacrylate is the type of cross linking agent used in PMMA denture base resin. The maim advantage of using cross linking agent is to increase the resistance of polymer to minute surface cracking or crazing. ${ }^{(16)}$

The addition of about $2-14 \%$ cross linking agent improves the resistance of acrylic resin to surface cracking, while the addition of up to $25 \%$ have little effect on tensile strength, transverse strength or hardness of acrylic plastic. ${ }^{(17)}$

Over the years, curing procedures have been modified with a view to improve the physical and mechanical properties of resin materials. Different polymerization methods have been used: heat, light, chemical and microwave energy. ${ }^{(18)}$ Various methods were presented for curing acrylic resin by heat and the most popular method is water bath. ${ }^{(14)}$ Some of the advantages of this methods are simple and low cost but the major disadvantage is long processing time required. ${ }^{(19)}$

The use of a pressure cooker for denture polymerization was first reported by Muley in $1976 .{ }^{(20)}$ Indian researchers extensively investigated the pressure cooker polymerization technique. Conventional acrylic resin material was used in this technique and required less than $1 \mathrm{~h}$ for polymerization and utilized conventional equipment. . $^{(2)}$

PMMA denture base resins and their curing processes have been modified not only to improve the physical and mechanical properties but also to improve the working properties. ${ }^{(22,23)}$

The autoclave processing technique is represents a better substitute for zwater bath technique. Regarding autoclave processing technique, the slow (long) curing cycle provides better denture bases material including the tested physical and mechanical properties as compared with the fast (short) curing cycle.(24)

This study was intended to investigate the effect of water bath and autoclave curing methods on transverse strength, tensile strength and surface roughness of cross linking acrylic denture base materials and to study the effect of time durations of autoclave (short and long) processing technique on these tests.

\section{MATERIALS AND METHODS}

The acrylic material used in this research was cross linking acrylic denture base material (SLEDGEHAMMER, KEYSTONE INDUSTRIES/ USA) and it was processed by two different heat curing methods water bath and autoclave.

Ninety specimens were prepared and grouped into: the control group (W) in which acrylic resin processed by conventional water bath processing technique at $74^{\circ} \mathrm{C}$ for 1.5 hours then boiled for 30 minutes and the experimental groups (A) in which acrylic resins processed by autoclave at $121^{\circ} \mathrm{C}, 210$ $\mathrm{KPa}$ (Kilopascal). The experimental groups were divided into autoclave short (AS) for 15 minutes and autoclave long (AL) for 30 minutes to study the effect of the autoclave processing, and three tests were conducted: transverse strength, tensile strength and surface roughness tests. For each test 10 specimens were used.

Metal patterns were constructed by cutting a stainless steel plate of $2.5 \mathrm{~mm}$ in thickness into the desired dimensions according to the requirements of each test, as follows:

The metal patterns were constructed for transverse strength test and surface roughness test with dimensions of $(65 \mathrm{~mm} \times 10 \mathrm{~mm} \times 2.5 \mathrm{~mm})$ length, width and thickness respectively ${ }^{(25)}$, and for tensile strength test with dimensions of $(65 \mathrm{~mm} \mathrm{X} 12.5 \mathrm{~mm} \mathrm{X}$ $2.5 \mathrm{~mm}$ ) length, width, and thickness respectively and the constricted part with $5 \mathrm{~mm}$ in width. ${ }^{(26)}$

The conventional flasking technique for complete dentures was followed in mold preparation for each sample. Each metal pattern was coated with petroleum jelly and immersed in the slurry stone (TYPE III HARD STONE, THIXOTROPIC, Zhermach/ Italy), which was prepared according to the manufacturer's instructions and poured into the lower half of the dental flask as in (Figure 1,2). The set lower half was coated with a separating medium(DIVOSEP, VERTEX-DENTAL/Netherlands) and allowed to dry and another layer of stone was poured into the second half of the flask and allowed to stand for one hour 
then the flask was opened and the metal block was removed.

The metal patterns were then removed from the flask being packed and the two halves of the mold were coated with a separating medium before packing with cross linking acrylic (SLEDGEHAMMER, KEYSTONE INDUSTRIES/USA). The material was mixed and manipulated according to the manufacturer's instructions $(3: 1)$ by volume and left under pressure 20 bar (100 Kilopascal $(\mathrm{KPa})$ for 5 minutes before clamping was done. Curing for the control group (W) was carried out by placing the clamped flask in a water bath and processed by short curing cycle 90 minutes at $74 \mathrm{C}^{\circ}$ then temperature was increased to the boiling point $100^{\circ} \mathrm{C}$ for 30 minutes. (25)

The curing for the experimental group (A) was carried out by placing the clamped flask in a fully automatic autoclave (SW 22 PLUS, STERN WEBER/ Italy) as shown in Figure (3) and processed by the preprogrammed cycles of two durations, as follow:(AS):Short $121^{\circ} \mathrm{C} / 210 \mathrm{KPa}, 15 \mathrm{~min}$. and (AL):Long $121^{\circ} \mathrm{C} / 210 \mathrm{KPa}, 30 \mathrm{~min}$. In this research, only two standard programs (short $121^{\circ} \mathrm{C} \&$ long $121^{\circ} \mathrm{C}$ ) were used for autoclave curing cycles.

The stages of operation of autoclaves included air removal, steam admission and sterilization cycle including heating up, holding/exposure, and cooling stages. ${ }^{(27,28)}$ The autoclave was operated to start heating the water, then the temperature and pressure were raised till they reached $\left(121^{\circ} \mathrm{C} \& 210\right.$ Kilopascal $)$ respectively. When the temperature reached $\left(121^{\circ} \mathrm{C}\right)$, the temperature and pressure were held automatically at $\left(121^{\circ} \mathrm{C}\right.$ and $210 \mathrm{KPa}$ respectively for 15 minute for short curing cycle and for 30 minutes for long curing cycle, then automatically exhausted the steam and the programmed cycle was finished. Finally, the metal flask was allowed to cool at room temperature for $30 \mathrm{~min}$., followed by complete cooling of the metal flask with tap water for $15 \mathrm{~min}$. before deflasking. The acrylic patterns were then removed from stone mold. (4)

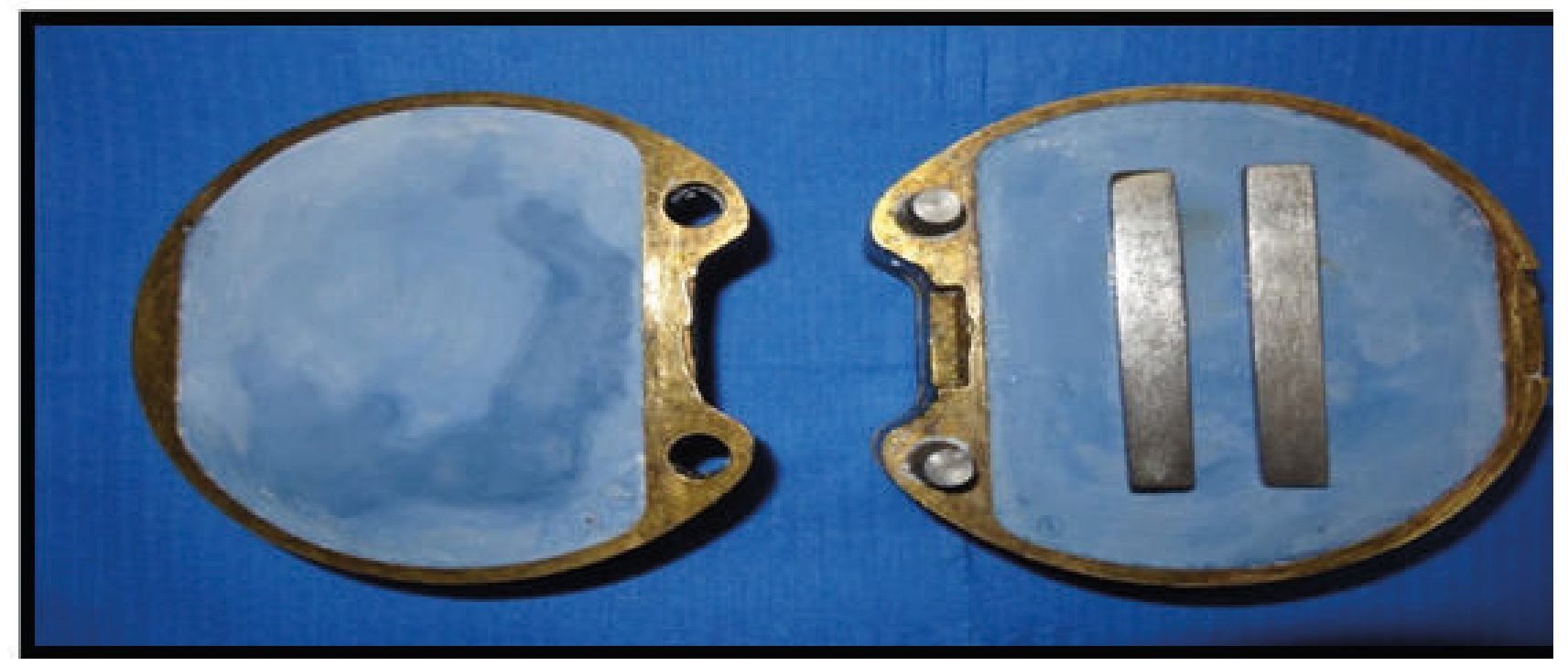

Figure (1) Metal pattern for transverse strength and surface roughness test in dental flask

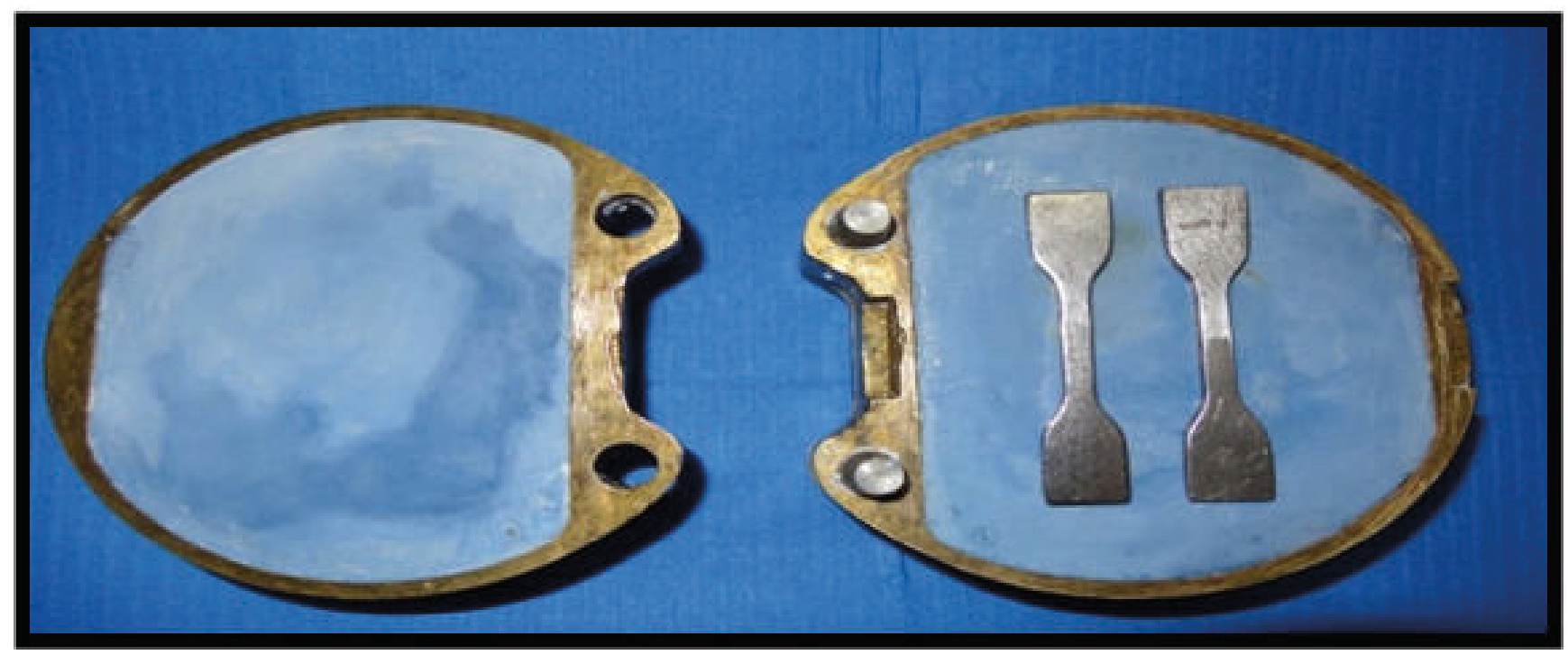

Figure (2) Metal pattern for tensile strength test in dental flask 


\section{Prosthodontics}

All the specimens were carefully de-flasked and finished except the specimens used for surface roughness test were not polished. All samples were placed in distilled water in an incubator for 48 hours at a temperature of $37{ }^{\circ} \mathrm{C}$ before they were tested. ${ }^{(25)}$

\section{Mechanical and physical tests:}

\section{Transverse strength test:}

The test was carried out by using the instron testing machine (Figure 4), each specimen was positioned on bending fixture, consisting of 2 parallel supports of $3.2 \mathrm{~mm}$ diameter placed (50) $\mathrm{mm}$ apart. The full scale load was $50 \mathrm{~kg}$ and the load was applied with cross head speed of $1 \mathrm{~mm} / \mathrm{min}$ by rod placed centrally between the supports making deflection until fracture occurred.

The transverse bend strength was calculated in $\mathrm{N} / \mathrm{mm}^{2}$ using the following formula:

\section{$\mathbf{S}=\mathbf{3 P L} / \mathbf{2 b d}^{\mathbf{2}(29)}$}

\section{Where}

S: Transverse strength $\mathrm{N} / \mathrm{mm}^{2}$ (Newton per square millimeter) or $\mathrm{MPa}$ (Megapascal)

P: is the peak load in Newton, L: is the span length in millimeter, $\mathrm{b}$ : is the sample width in millimeter, $\mathrm{d}$ : is the sample thickness in millimeter.

\section{Tensile strength test:}

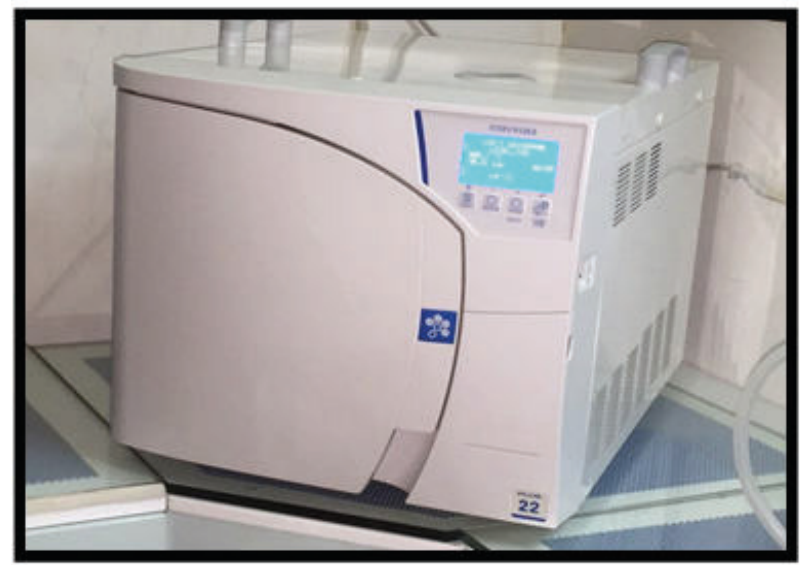

Figure (3) Autoclave

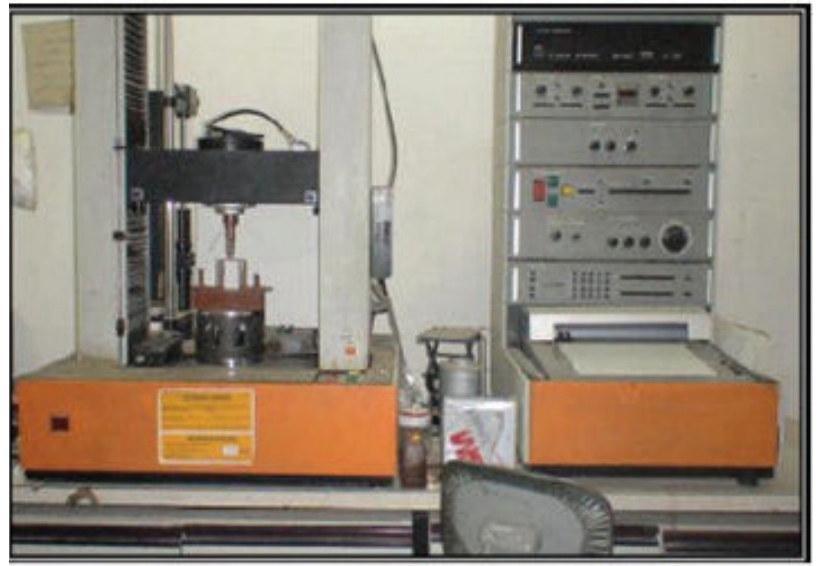

Figure (4) Instron testing machine for transverse strength test
The test was carried out by using the instron testing machine with grips suitable for the test specimens (Figure 5) and the load was applied with cross head speed of $1 \mathrm{~mm} / \mathrm{min}$. The specimens were tested with a full scale load of $50 \mathrm{~kg}$.

The tensile strength was calculated by the following formula:

$\mathbf{T} . \mathbf{S}=\mathbf{F}(\mathbf{N}) / \mathbf{A}(\mathbf{m m})^{2}$

T.S: tensile strength $\left(\mathrm{N} / \mathrm{mm}^{2}\right)$,

Where

[F: peak load (Newton), A: cross sectional area $\left.\left(\mathrm{mm}^{2}\right)\right]^{(4)}$

\section{Surface roughness test:}

A digital profilometer device (Surface roughness tester, TR200)(Figure 6) it was used to measure the surface roughness of the specimens. After deflasking, all the specimens were left unpolished. Each specimen was placed on a fixed and stable base and the device was placed in a way so that the stylus just touched the surface of the specimen. The stylus was then moved along the specimen surface for $10 \mathrm{~mm}$ length to generate the reading for that specimen. The surface roughness test was measured by a micrometer $(\mathrm{Mm})$. Statistical analysis was conducted with descriptive statistics, independent sample test, one-way (ANOVA) and multiple comparison tests utilizing the least significant difference test (LSD).

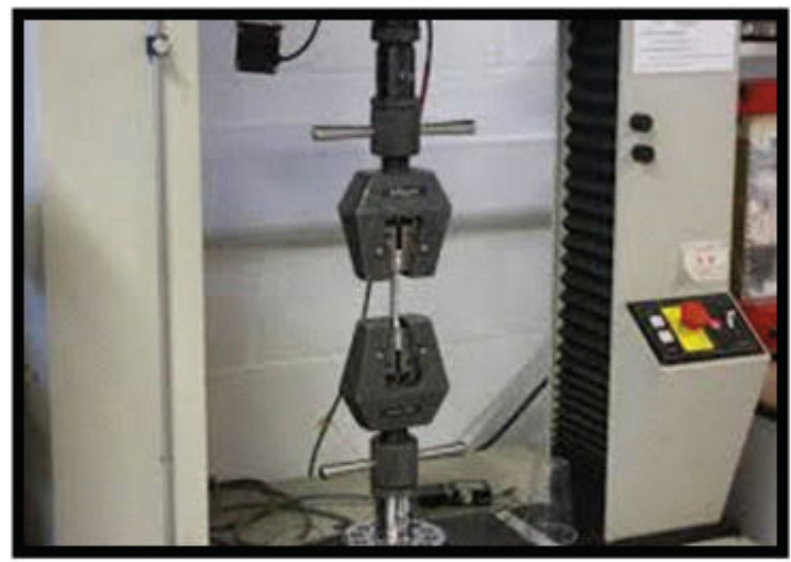

Figure (5) Instron testing machine for tensile strength test

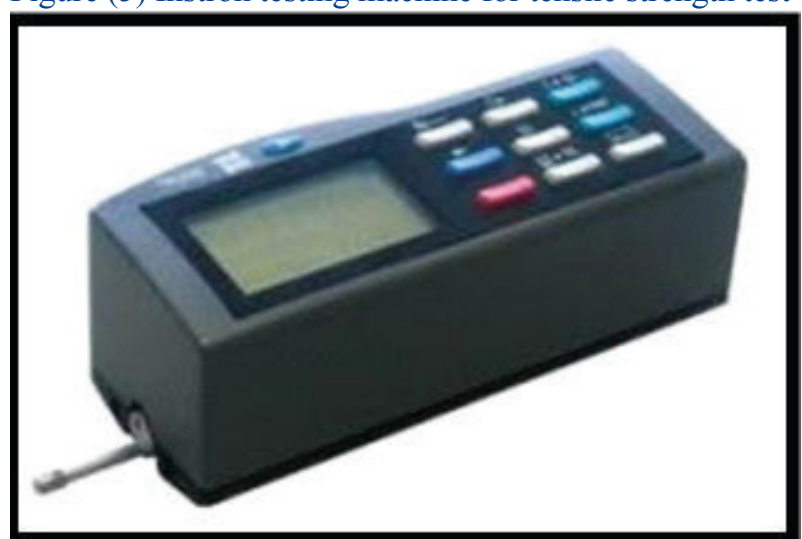

Figure (6) Digital profilometer device for surface roughness test 


\section{RESULTS}

The mean values of transverse strength and standard deviation for each studied group are presented in table (1).One-way ANOVA test showed no significant difference $(\mathrm{P}>0.05)$ between the means of the samples of all the test groups; autoclave processing slow, autoclave processing fast, and water bath group (Table 2).

The means and standard deviations for tensile strength for the samples of the experimental groups are presented in table (3). The mean difference between the different groups was insignificant $(\mathrm{P}>0.05)$ (Table 4).

The mean values and standard deviations for the experimental groups of surface roughness test are presented in table (5). One-way ANOVA test revealed that there was a highly significant difference $(\mathrm{P}<0.01)$ between the means of the test groups, as shown in Table (6). The samples processed in the autoclave with the short cycle had the highest readings $(3.0622 \mathrm{Mm})$ for the surface roughness and were highly significantly different $(\mathrm{P}<0.01)$ compared with those of the water bath processing cycle, which had the lowest readings $(1.8716 \mathrm{Mm})$. The mean of the surface roughness readings for the samples processed with the long autoclave cycle were in-between $(2.722 \mathrm{Mm})$ and were significantly different $(\mathrm{P}<0.05)$ when compared with that of the water bath processing cycle. On the other hand, both the autoclave processing cycles were insignificantly different $(\mathrm{P}>0.05)$ when their means were compared. The (LSD) comparison among the groups is shown in Table (7).

\section{DISCUSSION}

According to the results obtained from this study and in regard to the experimental group and control groups of cross linking acrylic related to transverse strength test and tensile strength test, there was a nonsignificant difference between the autoclave of the two cycles (AL and AS) and water-bath (W) curing methods; this may be related to fact that this type of acrylic denture base material made in high degree of homogeneity that leads to absence of any changes occurred within this material. The type of bonds among the molecules of this type of acrylic resin is also more stable under higher temperatures. ${ }^{(30)}$ Also the type of acrylic used in present study contains a cross linking agent which provides a sufficient number of bridges between linear macromolecules to form a three-dimensional network that increases the strength and rigidity of the resin. ${ }^{(29)}$

The results of this research showed no significant difference in transverse strength test between the means of the samples of all the test groups; autoclave processing long (AL), autoclave processing short (AS) and water bath (W) group. The results of this study were in agreement with Salwan ${ }^{(24)}$, who found nosignificant difference in transverse strength between autoclave and water-bath curing methods when using Vertex acrylic but he found there was a highly significant difference in transverse strength between autoclave and water bath processing methods when using high impact acrylic because this type of acrylic is modified by adding a rubber compound to improve strength properties. ${ }^{(7)}$ The result of this study is not in agreement with Durkan et $\mathrm{al}^{(31)}$, how studied the effect of autoclave polymerization on the transverse strength of high impact denture base polymers, the results revealed that polymerization in an autoclave led to a statistically significant increase in transverse strength for the materials evaluated when compared to the water bath. These conflicting results are due to using another curing cycle of autoclave processing. First they used autoclave-cured for $60^{\circ} \mathrm{C} / 30 \mathrm{~min}$ followed by $130^{\circ} \mathrm{C} / 10 \mathrm{~min}$, then they used autoclavecured for $60^{\circ} \mathrm{C} / 30 \mathrm{~min}$ followed by $130^{\circ} \mathrm{C} / 20 \mathrm{~min}$

The tensile strength test is an important test which determines the resistance of the material to tensile or stretching force. ${ }^{(32)}$. Materials having a combination of reasonable tensile strength and elongation will be the tough material and those with low elongation will be brittle material. ${ }^{(4)}$

Furthermore, it is important to determine the surface roughness of the materials used for dental prostheses before their use in the mouth. Rougher surfaces can cause discoloration of the prosthesis, be a source of discomfort to patients and it may also contribute to microbial colonization and biofilm formation. Bacterial and fungal species have more of a propensity to adhere to rough denture base materials. ${ }^{(33,34)}$ The surface roughness of a material used for removable prostheses is of importance because it affects, directly or indirectly; retention, staining resistance, plaque accumulation, oral tissue health, and patient comfort. ${ }^{(35,36)}$

On the other hand, the results of this study showed that polymerization in the autoclave led to a statistically significant difference in surface roughness test that indicate at this level of heat and pressure of autoclave processing cycle the beginning of reaction of the material to external elements. ${ }^{(37)}$ These results was not in agreement with Manar et $\mathrm{al}^{(38)}$, which revealed a non-significant difference between the water bath and the autoclave curing method may be 


\section{Prosthodontics}

due to using another processing cycle of autoclave $120^{\circ} \mathrm{C}$ under 1.4 bar for 45 minutes and using another type of material (Vertex).

\section{CONCLUSION}

Our findings showed that there was no significant difference between the autoclave of the two cycles (long and short) and water-bath curing methods regarding transverse strength test and tensile strength test, but there was a significant difference between the results of surface roughness tests.

Regarding surface roughness tests, it was concluded there was a highly significant difference between the samples processed in the autoclave with the short cycle compared with the control group but there was a significant difference between the samples processed in the autoclave with the long cycle compared with the control group.

Table 1: descriptive statistics of transverse strength test $\left(\mathrm{N} / \mathrm{mm}^{2}\right)$

\begin{tabular}{|c|c|c|c|c|c|c|}
\hline Curing type & Mean & $\boldsymbol{N}$ & S.D. & Min & Max & S. $\boldsymbol{E}$. \\
\hline water bath & 84.36800 & 10 & 10.819730 & 67.660 & 98.800 & 3.421499 \\
\hline autoclave long & 89.07800 & 10 & 7.815524 & 82.630 & 101.770 & 2.471486 \\
\hline autoclave short & 84.52800 & 10 & 8.212682 & 78.780 & 99.970 & 2.597078 \\
\hline
\end{tabular}

Table 2:One-way ANOVA for transverse strength between test groups

\begin{tabular}{|c|c|c|c|c|c|}
\hline transverse strength & Sum of Squares & d.f. & Mean Square & F-test & p-value \\
\hline Between Groups & 143.041 & 2 & 71.520 & .874 & .429 \\
\hline Within Groups & 2210.374 & 27 & 81.866 & & \\
\hline Total & 2353.415 & 29 & & \\
\hline
\end{tabular}

Non-significant $\mathbf{P}>\mathbf{0 . 0 5}$

Table 3: descriptive statistics of tensile strength test $\left(\mathrm{N} / \mathrm{mm}^{2}\right)$

\begin{tabular}{|l|c|c|c|c|c|c|}
\hline \multicolumn{1}{|c|}{ Curingtype } & Mean & $\boldsymbol{N}$ & S.D. & Minimum & Maximum & S.E. \\
\hline water bath & 31.05000 & 10 & 8.973789 & 20.000 & 44.080 & 2.837761 \\
\hline autoclave long & 34.39000 & 10 & 4.254300 & 28.750 & 41.070 & 1.345328 \\
\hline autoclave short & 33.12200 & 10 & 3.982402 & 28.100 & 37.650 & 1.259346 \\
\hline
\end{tabular}

Table 4:One-way ANOVA for tensile strength between test groups

\begin{tabular}{|l|c|c|c|c|c|}
\hline \multicolumn{1}{|c|}{ tensile strength } & Sum of Squares & d.f. & Mean Square & F-test & p-value \\
\hline Between Groups & 56.855 & 2 & 28.428 & .745 & .484 \\
\hline Within Groups & 1030.387 & 27 & 38.162 & \\
\hline Total & 1087.243 & 29 & & \\
\hline
\end{tabular}

Non-significant $\mathbf{P}>\mathbf{0 . 0 5}$

Table 5: descriptive statistics of surface roughness test (Mm)

\begin{tabular}{|l|c|c|c|c|c|c|}
\multicolumn{1}{c|}{ Curing type } & Mean & N & S.D. & Minimum & Maximum & S.E. \\
\hline water bath & 1.87160 & 10 & .397351 & 1.323 & 2.438 & .125653 \\
\hline autoclave long & 2.72200 & 10 & .916296 & 1.615 & 3.793 & .289758 \\
\hline autoclave short & 3.06220 & 10 & .711704 & 2.265 & 3.949 & .225061 \\
\hline Total & 2.55193 & 30 & .852128 & 1.323 & 3.949 & .155577 \\
\hline
\end{tabular}

Table 6:One-way ANOVA for surface roughness between test groups

\begin{tabular}{|l|c|c|c|c|c|}
\hline \multicolumn{1}{|c|}{ surface roughness } & Sum of Squares & d.f. & Mean Square & F-test & p-value \\
\hline Between Groups & 7.521 & 2 & 3.761 & 7.501 & $.003^{* *}$ \\
\hline Within Groups & 13.536 & 27 & .501 & & \\
\hline Total & 21.058 & 29 & & & \\
\hline
\end{tabular}

Highly-Significant $\mathbf{P}<0.05 * *$ 
Table 7: Least significant difference (LSD) between test groups

\begin{tabular}{|l|c|c|c|c|}
\hline \multicolumn{1}{|c|}{ Curing type } & Curing type & Mean Difference & S.E. & \multicolumn{1}{c|}{ Sig. } \\
\hline water bath & autoclave long & $-.850400^{*}$ & .316650 & $.012 *$ \\
\hline & autoclave short & $-1.190600^{*}$ & .316650 & $.001 * *$ \\
\hline autoclave long & autoclave short & -.340200 & .316650 & .292 \\
\hline
\end{tabular}

$\mathbf{P}>0.05$ Non-Significant, $\mathrm{P} *<0.05$ Significant, $\mathrm{P} * *<0.01$ Highly Significant

\section{REFERENCES:}

1. Pryor WJ Methods of producing more life like dentuers, including the preparation and processing of acrylic resins.J. Am. Associ, 1941; 28(6): 894-898.

2. Wilson HJ, Mansfield MA, Health JR and Spence S Dental technology and materials. 8th ed. Oxford: Black well Scientific Publication; 1987: 312-23, p372.

3. Powers JM and Sakaguchi RL Craig's Restorative dental materials.13th Ed.Philadelphia, PA Mosby Co., 2012; Ch.8, Ch.9.

4. Craig RG and Powers JM Restorative dental materials. 11th Ed. St. Louis Mosby Co., 2002; Ch.21.

5. Anusivice KJ Philips Science of dental material 10th edition, WB Saunders Co. Philadelphia. 1996.

6. Jagger DC, Jagger RG, Allen SM and Harrison A $\boldsymbol{A n}$ investigation into the transverse and impact strength of high strength denture base acrylic resins. J. of Oral Rehabilitation, Blackwell Science Ltd. 2002; 29: 263-267.

7. Meng TR and Latta MA Physical properties of four acrylic denture base resin.J.Contem. Dent. Pract. 2005; 6(4): 93100

8. Arena CA, Evan DB and Hilton TJ Acomparison of bond strengths among chair side hard reline materials. J. Pros. Dent. 1993; 70(2): 126-131.

9. Kawara M, Komiyama D, KimotosKobayshi N, Kobayshi $\mathrm{K}$ and Kemoto $\mathrm{K}$ Distortion behavior of heat activated acrylic denture base resin in conventional and long lowertemperature processing method. J. Dent. Res. 1988; 77(6): 1446-1453.

10. Cuningham JL Shear bond strength of resin teeth to heat cured and light cured denture base resin. J. Oral. Rehab. 2000; 27: 312-316.

11. Jagger DC, Harrison A And Jand TK The reinforcement of dentures. J. Oral Rehabil, 1999; 26: 185-194.

12. Johastone ER, Nichols JI and Smith D E Flexural fatigue of 10 commonly used denture base resin. J. Pros. Dent. 1981; 46: 478-483.

13. Carroll CE and Von Fraunhofer JA Wire reinforcement of acrylic resin prosthesis. "J.Pros. Dent. 1984; 52: 639-641.

14. Rodford RA The development and evaluation of high impact strength denture base material. J. of Dental Research. 1986; 14:124-157.

15. Harrison A, Huggett R and Jagger RC The effect of cross linking agent on abrasion resistance and impact strength of an acrylic resin denture base material. J. Dent. 1978; 6: 299-304.

16. Hill RG The cross linking agent ethylene glycol dimethacrylate content of the currently available acrylic denture base resin. J. Dent. Res.1981; 60(3): 725-726

17. Craig RG Restorative dental materials.10th Ed. St. Louis Mosby Co., 1997: 127-136, 500-540.

18. Azzari MJ,Cortizo MS and Alessandrini JL Effect of the curing conditions on the properties of an acrylic denture base resin microwave polymerized. J. Dent. 2003; 31: 463468.

19. Banerjee R, Banerjee S, Prabhudesai PS and BhideSV Influence of the processing technique on the flexural fatigue strength of denture base resins $A n$ in vitro investigation. Indian Dent Assoc. 2010; 21: 391-5.

20. Sidhaye $\mathrm{AB}$ Polymerization shrinkage of heat cured acrylic resins processed under steam pressure. Indian Dent Assoc.1981; 53: 49-51.

21. Undurwade $\mathrm{JH}$ and Sidhaye $\mathrm{AB}$ Curing acrylic resin in a domestic pressure cooker: $A$ study of residual monomer content. Quintessence Int.1989; 20(2): 123-129.

22. Takamta T, Setcos JC, Philips RW, and Boone ME Adaptation of acrylic resins dentures as influenced by the activation mode of polymerization. J. American Dental Associ. 1989; 119(2): 271-276.

23. Sadamori S, Ganefiyanti T, Hamada T, and Arima T Content of denture base cured by three processing methods. J. prosthet. Dent. 1994; 72: 19-22.

24. Salwan SA The effect of autoclave processingon some properties of heat cured denture base materials. A master thesis, College of dentistry, Baghdad University, 2012.

25. American Dental Association Specification No.12 Guide to dental materials and devices. 1999; 10th Ed., Chicago, P: 32.

26. Salem SA Reinforced denture base material. $\mathrm{Ph}$. D. Thesis. University of Manchester, 1979

27. Judelson HS Operation of the autoclaves. ,An excellent overview of autoclave operation posted by Dr. Howard Judelson at University of California at Riverside.2004

28. Oyawale, FA and OlaoyeAE Design and Construction of an Autoclave. Pacific Journal of Science and Technology. 2007; $8(2): 224-230$.

29. Anusavice KJ Phillips's sciences of dental materials. 11thEd. Saunders Co. Philadelphia, 2007: 162-169.

30. Walker KA, Morkoski LJ and Deeter GA Crosslinking chemistry for high- performance polymer network. Polymer. 1994; 35: 5012-7

31. DurkanR, Ozel MB, Bagis B and UsanmazA In vitro, Comparison of autoclave polymerization on the transverse strength of denture base resins. Dental Materials J. 2008; 27(4): 640-642.

32. O'Brien WJ and Ryge. An outline of dental materials and their selection.1978, Philadelphia, London.

33. Radford DR, Sweet SP, Challacombes and Walter JD Adherence of candida albicans to denture base materials with different surface finishes. J Dent; 1998; 26: 577-583.

34. Quirynen M, Marechal M, Busscher HJ, Weerkamp AH, Darius PL and Van Steenberghe D The influence of surface free energy and surface roughness on early plaque formation: an in vivo studyin man. J ClinPeriodontol 1990; 17: 138-144.

35. Ravnholt $G$ and Kabber $S$ Surface roughness of oral mucosa and its reproduction in dental materials. J Dent 1994; 22: 169-174.

36. Craig RG Restorative Dental Materials. 11th ed. St Louis, MO: Mosby; 2002: 87-88

37. Manappallila JJ Basic dental materials.2nd edition ch8, ch20, 2007:99-142, 346-377. New Delhi

38. Manar NY Nazhat, Tariq.YQ Basshi Amer.A Taqa $\boldsymbol{A n}$ Autoclave Effect on the Powder of Poly Methylmethacrylate. International journal of dental sciences and research 2014; 2(3). 